\title{
Desenvolvimento de um modelo de análise das perspetivas da Ciência, do Indivíduo e da Sociedade no Ensino das Ciências
}

\author{
Desarrollo de un modelo de análisis de las perspectivas de la Ciencia, del Individuo y de la \\ Sociedad en la Enseñanza de las Ciencias
}

\section{Development of an Analysis Model from the Perspectives of Science, Individual and Society in the Teaching of Science}

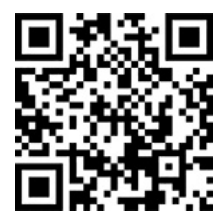

\author{
José Manuel do Carmo ${ }^{1}$ \\ Universidade do Algarve \\ Escola Superior de Educação e Comunicação \\ Tavira, Portugal \\ jmbcarmo@gmail.com
}

Recibido 4 de setiembre de 2015 • Corregido 1 de noviembre de 2016• Aceptado 27 de noviembre de 2016

\begin{abstract}
Resumo: A visão sobre as aprendizagens em Ciências que são consideradas básicas tem evoluído na medida da evolução dos conceitos de cultura científica e da natureza da educação em ciências. De um modelo essencialmente baseado na aquisição de informação organizada na lógica da ciência, a educação em ciências passou a incluir a prática do método da ciência quando se entendeu dar ênfase ao desenvolvimento de competências pessoais nos processos de pensamento e ação. A preocupação com a formação dos cidadãos em matérias relacionadas com a relação ciência-sociedade, e a participação social esclarecida implicou uma atenção especial na pesquisa e intervenção dos alunos sobre o ambiente envolvente, urbano, tecnológico e natural. Nesta investigação procura desenvolverse um modelo integrador das organizações curriculares com base nestes três eixos ou perspetivas, Ciência, Individuo e Sociedade, e a partir dele construir uma matriz de análise capaz de permitir a análise de propostas curriculares e planos de organização de unidades didática, bem como, apreciar as representações de professores sobre o ensino das ciências.
\end{abstract}

Palavras chaves: Análise curricular; ciência e sociedade; educação em ciência; ensino das ciências.

\footnotetext{
1 Máster en Educación, Universidad de Lisboa; Licenciado en Biología, Universidad de Lisboa; Fundador del Centro Ciencia Viva de Algarve y Fundador y Director del Centro Ciencia Viva de Tavira de 2004 a 2013. Director del Departamento de Ciencias, Escola Superior de Educação e Comunicação, Universidade do Algarve. Portugal de 2009 a 2012. Especialista en formación de profesores, didáctica de las ciencias y producción de recursos educacionales y divulgación publica de las ciencias.
} 
doi: http://dx.doi.org/10.15359/ree.21-1.16

URL: http://www.una.ac.cr/educare

CORREO: educare@una.cr

\begin{abstract}
Resumen: La visión básica del aprendizaje en ciencias ha cambiado en la medida de la evolución de los conceptos de la cultura científica y de la naturaleza de la enseñanza de las ciencias. De un modelo esencialmente basado en la adquisición de información, la educación en ciencias ha incluido la práctica del método de la ciencia cuando se definió la importancia de poner énfasis en el desarrollo de competencias personales y en los procesos de pensamiento y acción. La preocupación por la formación de la ciudadanía en las cuestiones pertinentes a la relación entre ciencia y sociedad y la participación social esclarecida exigieron una atención especial en la investigación y participación estudiantil en temáticas sobre el medio ambiente urbano, natural y tecnológico. Esta investigación pretende desarrollar un modelo integrador de organizaciones curriculares con base en estos tres ejes o perspectivas: ciencia, individuo y sociedad. Se construye una matriz que pueda permitir el análisis de propuestas curriculares y planes de organización de unidades didácticas, así como apreciar las representaciones docentes sobre la enseñanza de la ciencia.
\end{abstract}

Palabras claves: Análisis curricular; ciencia y sociedad; educación en ciencias; enseñanza de las ciencias.

\begin{abstract}
The basic vision of learning science has changed as scientific culture concepts evolution and the nature of the teaching of science go along. From a model essentially based on information acquisition, science instruction has included the practice of the science method when the importance of emphasizing the development of personal skills, thinking processes, and action was considered. The concern about citizens' education in matters referring to the relationship between science and society and enlightened social participation demanded a special attention in investigation and in students' participation in issues related to urban, natural, and technological environment. This research seeks to develop an integrative model of curriculum organizations based on these three axes or perspectives: science, individual, and society. A matrix enabling the analysis of curricular proposals and organization plans of didactic units is built, as well as the observation of teachers' representations in the teaching of science.
\end{abstract}

Keywords: Curriculum analysis; science and society; education in science; teaching of science.

\title{
Introdução
}

Embora não nos questionemos sobre a existência de Ciências no Ensino Básico, importa que se reflicta no papel que as Ciências desempenham na educação básica; importará reflectir em particular sobre que aprendizagens são consideradas básicas o cidadão adquirir numa escolaridade que vai até à adolescência; que formação em ciência se quer incentivar em alunos que após o $9^{\circ}$ ano abandonarão a escola ou, se continuarem, provavelmente não seguirão disciplinas científicas.

À escolaridade básica é pedido que proporcione à generalidade dos cidadãos os conhecimentos e oportunidades de desenvolvimento de capacidades necessárias para se orientarem nesta sociedade complexa, compreendendo o que se passa, tomando posição e intervindo. Se no inicio do sec XX se poderia acreditar que saber ler, escrever e contar resolveriam o analfabetismo e se promoveria o desabrochar de uma cidadania esclarecida (Monteiro, 1977), 
tem-se hoje consciência que a escolaridade básica tem que proporcionar à generalidade dos cidadãos as oportunidades de desenvolvimento de capacidades e os conhecimentos necessários para se orientarem nesta sociedade complexa, que pelo menos, permita lidar com diversos aspetos da vida quotidiana, compreendendo o que se passa, tomando posição e intervindo e para esse propósito, requere-se uma_Educação em Ciência que contribua com os recursos intelectuais da Ciência para o desenvolvimento do Homem como ser humano e para uma cidadania esclarecida (Hurd, 1970; Rubba,1982).

Esta frase apresenta uma formulação geral que sintetiza as diversas razões que justificam o ensino das Ciências na formação básica. Embora ambígua e pouco operacional, não deixa de se encontrar nela três referências que destaco: desenvolvimento do Homem como ser humano; recursos intelectuais da Ciência; cidadania esclarecida.

O projecto Synthesis procurou delinear o panorama do ensino das ciências nos Estados Unidos da América no final dos anos 70 e propor recomendações para o futuro. De entre o conjunto de trabalhos produzidos destaca-se a identificação na literatura dos principais objectivos, ou propósitos gerais atribuídos ao ensino das ciências e a sua sistematização em quatro grandes agrupamentos de propósitos: Necessidades pessoais, necessidades societais, preparação académica e educação/despertar para as profissões (Kahl e Harms,1980). O modelo empírico resultante foi posteriormente utilizado para contrastar o "ensino desejado" com o "estado actual" do ensino nos Estados Unidos da América. Se neste estudo, o ensino das ciências existente no final da década de 70 aparece caracterizado pelo domínio da preocupação com a preparação académica (Harms, 1980; Piel, 1980; Hurd, 1980; Welch, 1980), os movimentos de reforma curricular dos anos 80 vieram atribuir maior importância às restantes necessidades. Em particular o movimento CTS-Ciência,Tecnologia e Sociedade (Science/technology/society: A new effort for providing appropriate science for all, 1990; Hurd, 1991; 1998) é apontado como respondendo de modo mais equilibrado às necessidades actuais do ensino das ciências (Hurd 1998; Cachapuz, Praia e Jorge, 2004; Roso e Auler, 2016). Todavia, não obstante este desejo de equilíbrio, Santos (2007) identifica nos diferentes autores e nas propostas curriculares decorrentes, uma oscilação entre um maior enfase no compreender o conteúdo científico e no desenvolvimento de habilidades em relação à atividade científica, ou, noutra perspetiva, um maior enfase na aquisição de conhecimentos, habilidades e valores para compreender a função social da ciência. Também na visão dos professores sobre o conteúdo da Educação em Ciências e das práticas CTS se verifica uma imagem distorcida, empobrecida e equivocada (FerreiraGauchía, Vilches y Gil-Pérez, 2012; Tuay e Porras, 2015; Ozdem-Yilmaz e Cavas, 2016).

Retomando o trabalho do projecto Synthesis, foi proposto (Barbosa, Carmo, Cruz, Guimarães e Pereira, 1989) um modelo confrontando três perspectivas: A perspectiva da Ciência, o conjunto dos cientistas e das suas organizações; a perspetiva do Indivíduo, neste caso educando, isto é, aquele que vai à escola para ser educado; a perspectiva da Sociedade, isto é, o 
doi: http://dx.doi.org/10.15359/ree.21-1.16

URL: http://www.una.ac.cr/educare

CORREO: educare@una.cr

que queremos todos nós que as pessoas saibam para melhor desempenharem o seu papel no conjunto da comunidade. Embora coexistindo de modo integrado, a ênfase que uma ou outra destas diferentes perspetivas possam adquirir, ditarão diferentes orientações para o ensino das ciências. Procuramos neste trabalho, a partir desta abordagem, desenvolver um modelo de análise curricular que permita um instrumento útil para a identificação nos programas e na organização do ensino das perspectivas referidas.

\section{Desenvolvimento de um modelo de análise}

\section{A perspectiva da Ciência}

Muitos professores possuem uma formação-base científica numa determinada área do saber. Na sua formação, o importante era adquirir um conhecimento sólido dos diferentes ramos dessa ciência implicando, tanto o domínio do conhecimento actual, bem como dos limites e fronteiras que determinam os rumos dos progressos futuros. Esta formação era destinada também a fomentar o domínio das metodologias de experimentação e reflexão próprias. Os professores possuem, assim, uma formação científica básica para se tornarem profissionais dessa ciência, tanto no terreno da produção científica, como no da sua utilização técnica ou tecnológica.

Como professores tenderão a reproduzir o ensino que lhes foi ministrado. Tenderão a entender ser o seu papel reproduzir a aquisição pelos seus alunos dos conhecimentos básicos da ciência numa gradual e bem organizada espiral que os leva da ciência geral à discriminação das diferentes disciplinas. Procurarão basear a lógica de organização dos conteúdos para o ensino, na reprodução da lógica de interligação e discriminação conceptual que de algum modo constitui a lógica do desenvolvimento da própria ciência, segundo o entendimento dos próprios cientistas. Simularão simplificações das experimentações e comunicarão um método científico estereotipado. Procurarão enfim, reproduzir o percurso da sua própria formação e, se tiverem sucesso como professores, promoverão a formação de indivíduos com uma melhor compreensão, não só dos conteúdos e métodos de trabalho da Ciência atual, mas também da evolução das conceções sobre a sua natureza (Porlán, Rivero y Martín, 1998; Cachapuz et al., 2004), como do papel da Ciência na sociedade actual, capazes de constituir uma base social e política de apoio ao financiamento do empreendimento científico e desenvolverão em alguns alunos a motivação cognitiva e afectiva para continuarem a subir a escada da formação científica. Serão professores de Ciências no sentido de serem professores para pequenos cientistas, ou formadores científicos para crianças que irão engrossar o público dos cursos de ciências, tão necessários para garantir o contínuo desenvolvimento das ciências e a formação de crescente número de técnicos e tecnólogos capazes de dar resposta às necessidades do nosso tempo. Nesta perspectiva, numa visão disciplinar, o Ensino das Ciências procurará dar resposta às necessidades da Ciência (Santos, 2007). É um ensino para a Ciência. 
As reformas curriculares dos anos 60 nos países anglófonos, que posteriormente marcaram a perspectiva dominante e politicamente correcta no campo da educação científica, foram marcadas pela reconceptualização dos conteúdos, passando a procurar o aprofundamento em matérias limitadas, procurando a aquisição de conceitos específicos, capazes de veicular no sentido de transmitir concepções fundamentais da estrutura das disciplinas e da unidade e natureza da ciência. Neste sentido os conteúdos organizam-se em torno de grandes generalizações como, em Biologia (BSCS-Biological Science Curriculum Study), continuidade genética ou homeostasia, (Schwab e Klinckman, 1970). O ensino prescreve o papel activo do aluno na descoberta de um conhecimento que se pretende heurístico e organizando hierarquicamente as aquisições de conteúdos segundo a lógica conceptual das disciplinas e suscitador de aprendizagens significativas, na linha de Ausubel, Gagné e Bruner. Assim o aluno investiga e experimenta, vivenciando a actividade científica e socializando-se com ela enquanto desenvolve processos de pensar típicos da actividade científica. O aluno contacta com problemas sociais da actualidade, sobretudo para adquirir sobre eles o ponto de vista da ciência, isto é os conhecimentos que a ciência permite ter sobre eles. Um olhar científico do mundo acompanhado de uma apreciação positiva do papel da ciência na sociedade (Tamir, 1989; Hoffstein, 1985).

\section{A perspectiva do Indivíduo}

As investigações de Piaget, recorrendo a actividades de tipo prático envolvendo conceitos de carácter científico para estabelecer um sistema de desenvolvimento cognitivo, criaram as bases de um quadro metodológico para a utilização de actividades de tipo científico e experimental nas aulas. Estudos de psicologia educacional no desenvolvimento do racional piagetiano, mostram a possibilidade de promover o desenvolvimento psicológico da criança e a importância das actividades de ciências para facultar o treino de processos de pensamento. Usam-se, de algum modo actividades do tipo científico para demonstrar, caracterizar e desenvolver os modos de pensamento da criança. O processo da ciência com a sua objectividade e rigor, a sua exigência de dedução lógica, e também o seu apelo ao pensamento divergente e criativo capaz de encontrar construções mentais que se ajustem na estreita configuração de um problema a resolver, vieram a dar um sentido novo à importância do ensino das ciências no desenvolvimento da criança. As disciplinas de ciências contribuem também para o desenvolvimento de atitudes e valores que determinam comportamentos do indivíduo. A educação básica desejará que o indivíduo desenvolva atitudes, como a curiosidade, a exigência de fundamentação, a necessidade de prova para o julgamento, a persistência, entre outras. No desenvolvimento do seu processo de socialização, pretende-se que o indivíduo valorize, por exemplo, a cooperação e a consideração do ponto de vista dos outros. Estes são aspectos em que as ciências podem contribuir significativamente no conjunto do currículo para o desenvolvimento do indivíduo. A importância cada vez maior da ciência em todos os domínios da sociedade, requer que o indivíduo precise de aprender na escola a relacionar-se 
doi: http://dx.doi.org/10.15359/ree.21-1.16

URL: http://www.una.ac.cr/educare

CORREO: educare@una.cr

com a tecnologia e a adquirir a capacidade para usar a ciência na melhoria das suas vidas e para viver saudavelmente. Neste ponto de vista o ensino das ciências é visto na perspectiva das necessidades do indivíduo. É um ensino para o indivíduo.

Nos programas alinhados nesta perspectiva, as ciências não constituem um objectivo em si, mas sobretudo um contexto. Mais do que aquisições conceptuais específicas procuram treinar processos ou esquemas de pensamento como por exemplo, identificar e controlar variáveis, inferir generalizações, testar hipóteses, resolver problemas. Programas como CASE (Adey, Shayer e Yates 1989; Adey e Shayer, 1994), o projecto DIANOIA (Valente et al, 1989; Valente et al. 1991) ou o projeto ENEXP (Sá, Varela, Carvalho e Guimarães, 1999; Sá e Varela, 2007) situamse nesta perspectiva, assumindo-se como programas de desenvolvimento cognitivo e não como programas de ensino de ciências, se bem que nos exemplos referidos, as ciências sejam o conteúdo concreto das actividades propostas.

\section{A perspectiva da Sociedade}

Os meios de comunicação trazem até cada um de nós acontecimentos e preocupações sobre as quais se espera que cada cidadão possa entender o suficiente para não se considerar analfabeto. A exigência de uma sempre maior participação dos cidadãos na democracia exige um conhecimento mínimo dos problemas e opções que se põem à sociedade por forma a que cada um possa optar e votar fundamentadamente e participar de forma responsável em toda a vida da comunidade. Muitas das questões e problemas que se põem à Sociedade possuem uma componente científica, e frequentemente o problema reside mesmo na interacção ciência/ sociedade. Questões ambientais, questões relacionadas com as alternativas energéticas, questões ligadas a opções urbanísticas e de ordenamento, questões ligadas à promoção da saúde pública, são exemplos em que a escola, em particular o ensino das ciências pode contribuir para a cultura científica básica do cidadão. Se há necessidade de compreender o fundamento científico dos problemas e questões, das implicações das soluções alternativas e do potencial da ciência na resolução dos problemas, é preciso também compreender os limites e obstáculos à sua resolução: é uma educação para a cidadania.

Se é importante conhecer o trabalho dos cientistas e tecnólogos e contactar a vários níveis com o trabalho da produção científica, a sociedade requer também que se constate na escola como o binómio ciência-sociedade estrutura uma larga gama de profissões e carreiras. É também importante o conhecimento de como a ciência permeia um enorme número de profissões independentemente do grau de exigência académica e de como a competência no seu desempenho dependerá de uma contínua abertura à inovação e à formação. Neste ponto de vista o ensino das ciências deverá responder às necessidades da sociedade. É um ensino para a Sociedade. 
Tomando como exemplo o projecto curricular Science in Society (Lewis,1981), considerando que a educação em ciência tem feito pouco para demonstrar a relevância da ciência aprendida no laboratório da escola para o mundo exterior à escola, define como seu propósito dar uma melhor compreensão do papel da ciência e da tecnologia no mundo de hoje e uma consciência de que apenas pelo seu uso sensato se poderá garantir o futuro da humanidade. Diferentes movimentos se desenvolveram nesta perspectiva, como o CTS (Ciência, Tecnologia e Sociedade), Educação Ambiental ou Educação para a Saúde e Segurança.

Nesta linha os alunos estudam problemas concretos de caracter ambiental, recolhendo informações sobre os diversos aspectos do problema e os pontos de vista dos diversos intervenientes; contactam com as actividades humanas e as técnicas que utilizam; procuram conhecer os fundamentos científicos para compreender a informação disponível socialmente sobre, por exemplo cuidados de saúde, alimentação, consumo ou sobre controvérsias científicas em tópicos de relevância societal (Reis, 2013; Chacon, Ribeiro e Borges, 2016).

\section{Que fazer com a Tecnologia}

Levy (1999) refletindo sobre"O carácter problemático do termo tecnologia, ou como navegar entre a utopia e a distopia", sublinha que o termo se encontra numa tal variedade de contextos e âmbitos que "entre o mito, preciso e inatingível, e a identificação de um "topos", significado de uma pluralidade ou multiplicidade de significantes", importa restringir e clarificar sentidos.

A técnica dos "artistas", com um saber-fazer empírico e prático, evolui em tecnologia com a revolução industrial como uma cognição da prática traduzida numa "disciplina" do saber, que o sufixo "logia" especifica, associada às ciências que lhe dão fundamento: Da Mecânica, capítulo da Física, à engenharia mecânica. Evolui ainda como "metacognição" de uma prática cientificamente culta, para uma rotura epistemológica que lhe dá o estatuto de Ciência com objecto, conteúdo e metodologia próprias. Em alguma medida tende-se a ver nas tecnologias a aplicação prática de conhecimentos, todavia a tecnologia como ciência tem uma produção de conhecimentos conceptuais teóricos, típica da racionalidade a que chamamos conhecimento científico. Na polémica ciência pura versus ciência aplicada, a Agronomia, a Medicina ou a Biotecnologia não deixam de ter de ambas, sendo no entanto marcadas pela tónica de intervenção no mundo social real, tanto pelas problemáticas que as orientam, como pelos produtos que desenvolvem. Chamamos-Ihes "tecnologias", como frequentemente se associam outras em Ciências da Vida e da Terra, ou Ciências Naturais.

Voltando a utilizar o citado trabalho de Levy (1999), por um lado há uma visão da Tecnologia que lhe confere uma autonomia racional, aproximando-a das ciências e da matemática. Nesta visão, o valor, positivo ou negativo, é-lhe atribuído do exterior, a 
doi: http://dx.doi.org/10.15359/ree.21-1.16

URL: http://www.una.ac.cr/educare

CORREO: educare@una.cr

Tecnologia em si nada tendo a ver com escolhas normativas e, tal como as ciências naturais, pode ser considerada independente dos factores humanos. Mesmo quando se reclama os cidadãos deverem ter uma educação que Ihes permita uma participação activa nas discussões, estamos geralmente a pensar em conhecimentos e informações técnicas. Por outro lado há uma visão sociocultural da Tecnologia. Os percursos da tecnologia não são, nem lineares, nem obedecem apenas à racionalidade científica. Têm as marcas dos processos sociais em que se inserem. A racionalidade da ciência e tecnologia situa-se ao lado de outras dimensões da vida social e cultural que interferem mutuamente. $O$ desenvolvimento em ciência e tecnologia é ditado pelas instituições sociais dominantes (internacionais, governos, empresas e universidades), mas também há ciência e tecnologia determinada a partir de posturas ideológicas e sociais alternativas, cuja dimensão traduz o peso da influência que possuem no contexto global. Também neste aspecto, a tecnologia não parece distinguirse dos percursos da ciência, das ciências. Em ambas as conceções, mais restrita ou mais alargada, a ciência e a tecnologia, ou cada uma das ciências e tecnologias, têm um corpo de conhecimentos, uma racionalidade científica, um corpo de problemáticas, um corpo metodológico e um campo de debate filosófico sobre a natureza do seu saber que lhe são próprios e que constituem o seu ambiente epistemológico.

Na evolução recente do pensamento, Ciência e Tecnologia aproximam-se num complexo -Tecnociência- que esbate as oposições entre o puro e o aplicado e resolve a polémica entre a Ciência e a Tecnologia quanto ao papel recíproco no desenvolvimento do conhecimento e das técnicas. A separação entre ciência e tecnologia hoje não terá mais valor que o de um arquétipo. Como salienta M.E.Santos,

O termo tecnociências é a melhor forma de definir a "ciência pós-moderna". De facto, na investigação científica pós-moderna, a ciência e a tecnologia não são encaradas como entidades separadas. São encaradas em termos de um sistema cognitivo para a produção de novos conhecimentos. É a integração da ciência e da tecnologia que fornece uma distinção essencial entre a "ciência moderna" e a "ciência pós-moderna". (Santos, 1998, p. 79)

\section{Um quadro integrador}

Conforme olhemos para o ensino das ciências numa ou noutra destas perspetivas (ver figura1), se estabelecerão finalidades educativas distintas, de que decorrerão diferentes organizações curriculares, diferentes opções quanto a métodos de ensino e avaliação e diferentes modos de pensar dos professores, qualquer delas, isoladamente, apenas dando um ensino das ciências desequilibrado e parcial (Pereira et al., 1992). 
doi: http://dx.doi.org/10.15359/ree.21-1.16

URL: http://www.una.ac.cr/educare

CORREO: educare@una.cr

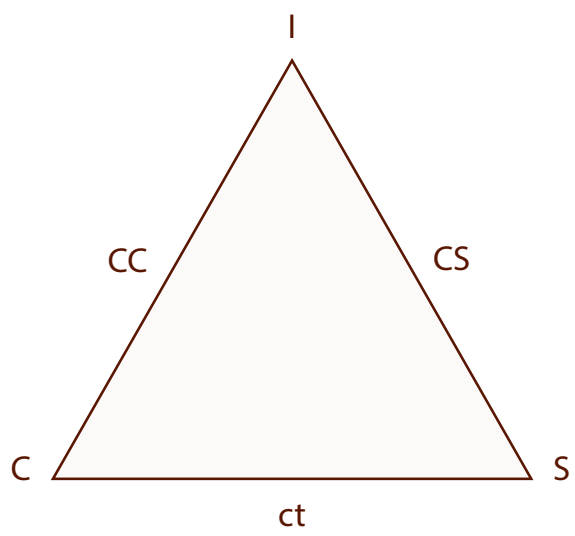

Figura 1: Diagrama articulando as três dimensões do modelo de análise -Ciência(C), Indivíduo(I) e Sociedade(S)-e respectivas interrelações cultura científica(cc), cultura social(cs) e cultura técnica(ct).

\section{As relações Ciência - Indivíduo - Sociedade.}

Neste diagrama as arestas também ganham um significado. A sociedade tem para com a ciência um olhar exterior: Quer compreender significados, quer ter representações dos fenómenos, quer respostas práticas, quer apreciar, quer valorizar, quer entender as implicações sociais, filosóficas e éticas das práticas e dos conhecimentos. Quer apreender a racionalidade científica para abordar os tópicos e problemas societais que se colocam. No caso da ovelha "Dolly", em que dificilmente se distinguirá a ciência da tecnologia, o que interessa aos cientistas, não é o mesmo que interessa à sociedade em geral. Da ciência pouco mais se precisará que uma formulação genérica do princípio da continuidade genética e de uma representação do ADN como duas fitas de carnaval. O que interessa fundamentalmente é compreender os propósitos e a utilidade desta ovelha, assim como a natureza concreta dos receios que levanta em relação com os valores ideológicos e morais mais gerais que lhe estão associados. O significado desta aresta é assim um ensino em ciências contextualizado na sociedade. A aresta CS, entre a ciência e a sociedade, estabelece a dimensão que designámos cultura técnica, se a virmos como traduzindo a procura de uma compreensão prática do meio envolvente e dos problemas que se põem, fundamentalmente utilizando o corpo de conhecimentos das ciências no entendimento da realidade. Um conhecimento de ciências utilitário e explicativo.

A aresta $\mathrm{Cl}$, concretiza a relação que se estabelece entre a ciência e o indivíduo. Um ensino que procura desenvolver as capacidades de pensamento em relação directa com a ciência: Aprendizagem conceptual na lógica da organização do conhecimento científico, desenvolvimento dos processos de pensamento científico em relação com trabalho prático de tipo laboratorial, resolução de problemas associados a conceitos científicos concretos 
doi: http://dx.doi.org/10.15359/ree.21-1.16

URL: http://www.una.ac.cr/educare

CORREO: educare@una.cr

e compreensão da natureza da ciência. É portanto um ensino em que se equilibram e complementam as preocupações com o desenvolvimento cognitivo do aluno e a formação na perspectiva da ciência como cultura. Retomando o exemplo do estudo do "caso Dolly", aproveitar a oportunidade para uma aprendizagem sistematizada dos conteúdos científicos relacionados, das metodologias usadas, dos contextos que levam à descoberta, constituem aspectos que se justificam pelo propósito de incentivar um enriquecimento pessoal em matéria de cultura científica. De algum modo representa a dimensão da cultura científica pessoal.

A preocupação com o desenvolvimento do Indivíduo orientada no sentido da sua relação social, pressupõe não só um desenvolvimento conceptual e de atitudes relevantes do ponto de vista da sociedade, mas também das capacidades de relacionamento e acção. Entre o indivíduo e a sociedade estabelece-se uma dimensão de participação e integração social e comunitária representada pela aresta IS, a que chamaremos cultura social.

\section{Discussão do modelo na leitura das tendências da educação em ciências}

As reformas dos anos 60 procuraram fazer os alunos sentirem-se cientistas caracterizandose por atribuírem um papel central ao laboratório; por considerarem o aluno activo, construindo conceitos por descoberta; por privilegiarem a capacidade para transferir conhecimentos e resolver problemas, por se focarem mais na compreensão dos conceitos mais gerais da ciência que na aquisição de conhecimentos concretos; por incidirem no desenvolvimento da capacidade para estudar os fenómenos naturais de modo objectivo, distinguindo evidência de propaganda e realidade de ilusão; por pretenderem desenvolver atitudes positivas para com a ciência e as carreiras científicas. É no essencial um ensino centrado na Ciência e no desenvolvimento do Indivíduo para a Ciência. Não se distingue assim do ensino das ciências tradicional, excepto por ser enquadrado numa perspectiva mais actualizada da ciência e por dar maior importância ao desenvolvimento do Indivíduo com o ênfase que é dado ao aluno e ao seu papel de agente activo na aprendizagem. A caracterização das reformas dos anos 60 pode ser entendida no modelo que se apresenta por um aumento do peso do pólo Indivíduo e da correspondente aresta $\mathrm{Cl}$ - cultura científica. A apreciação do relatório do projecto Synthesis sobre "ensino pelo inquérito" (terminologia usada na época da publicação em Portugal do BSCS), mostra bem como este ensino é essencialmente um ensino para a ciência e para o desenvolvimento de competências científicas no âmbito da ciência (Welch,1980).

As tendências de renovação do ensino das ciências dos anos 80 incentivaram um ensino de ciências mais preocupado em promover uma educação básica em ciências ou alfabetização científica (scientific literacy) em que uma pessoa educada possua uma compreensão básica em ciência de modo a poder tomar decisões informadas na sua vida diária e a funcionar eficazmente como cidadão (Klopfer,1985). Caracterizam-se por entender a aquisição e aplicação 
de conhecimentos relevantes num contexto social; o treino do uso dos "processos de pesquisa" (enquiry) em situações quotidianas e concretas, como instrumento pessoal para compreender, resolver problemas ou formar opinião sobre o meio de que faz parte; compreensão da natureza da ciência, sobretudo das relações entre a Ciência e a Sociedade. O vértice Sociedade do modelo ganha protagonismo, instituindo-se como pólo do modelo: A Ciência é aprendida em relação às necessidades ditadas pela perspectiva societal. Os conteúdos da ciência são aprendidos numa perspectiva prática, os processos da ciência são instrumentos de relacionamento com os fenómenos e situações do meio, a ciência é vista como uma instituição social na linha do que designámos cultura técnica ou tecnológica. A actividade dos alunos dirige-se para o envolvimento e pesquisa em temas ou questões de interesse social, procurando reforçar o seu sentido de pertença e de responsabilidade social. $O$ desenvolvimento das capacidades do Indivíduo orienta-se para a aquisição de uma cultura social. Em larga medida as várias modalidades do movimento CTS situam-se nesta tendência, por vezes dando maior ênfase à relação CS, outras dando relevo significativo à investigação e intervenção concreta pelos alunos em problemas e situações do seu meio envolvente, privilegiando a dimensão IS.

\section{Uma proposta de Matriz de Análise.}

Para operacionalizar o modelo procurou desenvolver-se para cada uma das referidas perspectivas, Ciência, Indivíduo e Sociedade, um inventário deafirmações traduzindo desideratos educativos ou características organizacionais do ensino que lhes fossem características que se descreve na tabela 1. Uma outra dimensão transversal foi considerada (Miguéns, Serra, Simões e Roldão,1996), pretendendo caracterizar o tipo de aquisição ou saber pretendido tendo-lhe sido atribuído três valores: saber; saber fazer e saber ser, correspondendo, respectivamente a aquisições de conteúdo, aquisições de processos e aquisições de atitudes e comportamentos. A leitura vertical de cada uma das colunas do quadro expõe três diferentes programas para o ensino de ciências, cada um deles apenas respondendo de modo parcial às necessidades actuais para o ensino das ciências. As nove categorias assim criadas constituem uma matriz de análise tornando possível uma apreciação da importância que adquirem as diferentes dimensões consideradas, assim como das suas inter-relações. Cada uma das asserções identificadas a partir da análise de conteúdos quanto aos propósitos educativos, seja de um programa, seja de um manual, seja a partir de uma reflexão sobre a prática de professores, poderão ser classificadas, numa dimensão, como C, I ou S, e noutra dimensão, como saber, saber-fazer ou saber-ser. As asserções categorizadas simultaneamente em duas dimensões $(C, I, S)$ são interpretadas como estabelecendo uma relação e portanto situando-se numa das arestas, sendo qualificadas como cs -cultura social se relacionam I e S, ct -cultura técnica, se estabelecem uma relação entre $C$ e $S$, ou cc -cultura científica, entre as dimensões I e C. 
doi: http://dx.doi.org/10.15359/ree.21-1.16

URL: http://www.una.ac.cr/educare

CORREO: educare@una.cr

Tabela 1: Categorias do modelo CIS e exemplos de asserções características de cada uma das categorias

\begin{tabular}{|c|c|c|}
\hline ia & duo & Sociedade \\
\hline Sabe & Saber & Saber (c \\
\hline $\begin{array}{l}\text { - Estruturação dos conhecimentos } \\
\text { segundo a lógica da Ciência. } \\
\text { - Aquisição de bases para a } \\
\text { continuação de estudos em Ciências. } \\
\text { - Compreensão da natureza da } \\
\text { Ciência. } \\
\text { - Conteúdos organizados em } \\
\text { Unidades de Ensino por tópicos } \\
\text { da Ciência. }\end{array}$ & $\begin{array}{l}\text { - Aquisição de conhecimentos para a } \\
\text { compreensão de si e do mundo. } \\
\text { - Compreensão dos acontecimentos } \\
\text { e situações do quotidiano. } \\
\text { - Conteúdos organizados em } \\
\text { Unidades de Ensino com base em } \\
\text { interesses ou situações. } \\
\text { - Desenvolvimento de uma base } \\
\text { cultural pessoal. }\end{array}$ & $\begin{array}{l}\text { - Aquisição dos conhecimentos científicos } \\
\text { para a compreensão de acontecimentos } \\
\text { e problemas da sociedade. } \\
\text { - Conhecimento das implicações } \\
\text { sociais de descobertas científicas. } \\
\text { - Aquisições essenciais de consumidor } \\
\text { esclarecido. } \\
\text { - Aquisições relativamente à saúde e } \\
\text { bem-estar. }\end{array}$ \\
\hline $\begin{array}{l}\text { - Aquisição de competências } \\
\text { para o trabalho e a utilização de } \\
\text { instrumentação laboratorial. } \\
\text { - Desenvolvimento dos processos } \\
\text { de pensamento na aprendizagem } \\
\text { dos conceitos científicos. } \\
\text { - Desenvolvimento da capacidade } \\
\text { de pensamento crítico e criativo } \\
\text { na resolução de problemas no } \\
\text { âmbito dos conceitos científicos. } \\
\text { - Desenvolvimento de competência } \\
\text { para seguir procedimentos } \\
\text { laboratoriais com autonomia. }\end{array}$ & $\begin{array}{l}\text { lidar com aparelhos e instrumentos } \\
\text { correntes. } \\
\text { - Desenvolvimento da capacidade para } \\
\text { utilizar os processos de pensamento } \\
\text { científicos na compreensão de } \\
\text { situações do quotidiano. } \\
\text { - Desenvolvimento da capacidade } \\
\text { para tomar decisões, expressar } \\
\text { opiniões e formular juízos de valor } \\
\text { de modo fundamentado. } \\
\text { - Desenvolvimento da capacidade para } \\
\text { procurar informações por si mesmo } \\
\text { sobre um assunto ou problema. }\end{array}$ & $\begin{array}{l}\text { - Desenvolvimento da capacidade para } \\
\text { obter informações sobre assuntos de } \\
\text { carácter social e funcionamento das } \\
\text { instituições. } \\
\text { - Identifica aspectos críticos no } \\
\text { quotidiano. } \\
\text { - Desenvolvimento da capacidade para } \\
\text { planear a acção para abordar uma } \\
\text { situação ou problema concreto e } \\
\text { apreciar os resultados. } \\
\text { - Desenvolvimento de competências } \\
\text { de participação e intervenção cívica. }\end{array}$ \\
\hline $\begin{array}{l}\text { Saber ser (atitudese } \\
\text { - Desenvolvimento do ir } \\
\text { explorar e aprofundar } \\
\text { ou assuntos científicos }\end{array}$ & $\begin{array}{r}-\mathrm{De} \\
\mathrm{co} \\
\mathrm{po}\end{array}$ & $\begin{array}{l}\text { s adequados } \\
\text { xemplo, à saúde, } \\
\text { hte. }\end{array}$ \\
\hline $\begin{array}{l}\text { - Desenvolvimento de atitudes } \\
\text { favoráveis relativamente às } \\
\text { profissões de carácter científico. }\end{array}$ & $\begin{array}{l}\text { volvimento de atitudes } \\
\text { ais de persistência e rigor no } \\
\text { ho. }\end{array}$ & $\begin{array}{l}\text { parcial da } \\
\text { olução dos } \\
\text { ide. }\end{array}$ \\
\hline $\begin{array}{l}\text { - Contacto com a actividade } \\
\text { científica que facilitem a visão da } \\
\text { Ciência como actividade humana. } \\
\text { - Contacto com situações que } \\
\text { permitam apreciar a importância } \\
\text { da Ciência no mundo. }\end{array}$ & $\begin{array}{l}\text { - Desenvolvimento da criatividade e } \\
\text { curiosidade individuais. } \\
\text { - Desenvolvimento de atitudes de } \\
\text { abordagem racional de situações. }\end{array}$ & $\begin{array}{l}\text { - Constatação do contributo da Ciência } \\
\text { num amplo espectro de profissões. } \\
\text { - Desenvolvimento de opinião com } \\
\text { base no equacionar de argumentos } \\
\text { em aspectos diversos. }\end{array}$ \\
\hline
\end{tabular}




\section{Conclusão}

O modelo proposto tem capacidade para explicar as sucessivas ondas no desenvolvimento curricular para o ensino de ciências. Se este modelo coincide com a investigação empírica dos anos 80, também mostra coincidir largamente com as conceções atuais sobre a natureza do conhecimento escolareascorrespondentestipologias deorganizaçãocurriculardoconhecimento. $\mathrm{Na}$ continuação deste trabalho se apresentará a confrontação com estudos sobre a imagem da ciência, nomeadamente com as desenvolvidas por investigadores atuais como os Grupos de Porlán e colaboradores (Porlán e Martín, 2004; Solís, Porlán e Rivero, 2012). Este modelo procura ser, essencialmente um instrumento para a análise de recursos educativos, nomeadamente, programas e manuais de ensino, procurando explicitar perspectivas dominantes na sua conceção, assim como apreciar a visão dos professores sobre o ensino praticado. A transformação da matriz de análise apresentada num inventário permitiu já a sua utilização experimental com grupos de professores e alunos-professores, cujo aprofundamento em curso se dará conta em outros trabalhos, em duas linhas de investigação. Por um lado a sua utilização na análise de programas de ciências do Ensino Básico em particular num âmbito de formação de professores. Por outro, para a caracterização do ensino praticado nas escolas na perceção dos professores. Em ambos os casos, este modelo constitui um instrumento para a reflexão sobre o papel do ensino de ciências na escolaridade básica e neste sentido ele poderá constituir um instrumento de análise de práticas e reflexão formativa com futuros professores ou com professores em exercício.

\section{Referências}

Adey, P. e Shayer, M. (1994). Really raising standards. Cognitive intervention and academic achievement. Londres: Routledge.

Adey, P., Shayer, M. e Yates, C. (1989). Thinking science: The curriculum materials of the cognitive acceleration through science education (CASE) project. Basingstoke, Londres: Macmillan Education.

Barbosa, M. V., Carmo, J. M. B., Cruz, M. N., Guimarães, H. M. e Pereira, M. P. (1989). Algumas reflexões sobre o ensino das ciências no $3^{\circ}$ ciclo do ensino básico. Revista de Ciência, Tecnologia e Sociedade, 8-9, 74-87.

Cachapuz, A., Praia, J. e Jorge, M. (2004). Da Educação em Ciência às orientações para o ensino das ciências: Um repensar epistemológico. Ciência \& Educação, 10(3), 363-381. doi: https:// doi.org/10.1590/S1516-73132004000300005

Chacon, E. P., Ribeiro, C. M. R. e Borges, M. N. (2016) "Jogo da Radiação": Elaboração de um software educativo articulado ao contexto CTSA e a percepção docente e discente. Ensino de Ciências e Tecnologia em Revista 6(1), 1-14. Recuperado de http://srvapp2s.urisan.tche. br/seer/index.php/encitec/article/view/1632/906 
doi: http://dx.doi.org/10.15359/ree.21-1.16

URL: http://www.una.ac.cr/educare

CORREO: educare@una.cr

Ferreira-Gauchía, C., Vilches, A. y Gil-Pérez, D. (2012). Concepciones docentes acerca de la naturaleza de la tecnología y de las relaciones ciencia, tecnología, sociedad y ambiente en la educación tecnológica. Enseñanza de las Ciencias, 30(2), 253-272. Recuperado de http:// www.uv.es/vilches/Documentos/EdIC\%202012.pdf

Harms, N. (1980). VIII. Project synthesis: Summary and implications for teachers. In N. C. Harms e R. E. Yager (Eds.), What research says to the science teacher (Vol. 3, pp. 113-127. Washington: National Science Teachers Association-NSTA.

Hoffstein, A. (1985). Science: Key concepts. Em T. Husén eT.N Postlethwaite(Eds.), The International encyclopedia of education (Vol. 8, pp. 4465-4466). New York: Pergamon Press.

Hurd, P. D. (1970). Scientific enlightenment for an age of science. The Science Teacher, 37(1), 13-15.

Hurd, P. D. (1980). III. Biology education. In N. C. Harms e R. E. Yager (Eds.), What research says to the science teacher (Vol. 3, pp. 12-32), Washington: National Science Teachers AssociationNSTA.

Hurd, P. D. (1991). Closing the educational gaps between science, technology, and society. Theory Into Practice, 30(4), 251-259. doi: https://doi.org/10.1080/00405849109543509

Hurd, P. D. (1998). Scientific literacy: New minds for a changing world. Science Education, 82(3), 407-416. doi: https://doi.org/10.1002/(SICl)1098-237X(199806)82:3<407::AIDSCE6 $>3.0 . C O ; 2-G$

Kahl, S. e Harms, N. (1980). II. Project synthesis: purpose, organization and procedures. In N. C. Harms e R. E. Yager (Eds.), What research says to the science teacher (Vol. 3, pp. 5-11). Washington: National Science Teachers Association.

Klopfer, L. E. (1985). Scientific literacy. Em T. Husén eT. N. Postlethwaite. International encyclopedia of education (Vol. 8, pp. 4478-4479). New York: Pergamon Press.

Levy, T. (1999). O carácter problemático do termo tecnologia, ou como navegar entre a utopia e a distopia. Revista de Educação, 8(2), 3-13.

Lewis, J. L. (1981). Science in society. Teacher's guide. Londres: The Association for Science Education.

Miguéns, M., Serra, P., Simões, H. e Roldão, M. C. (1996). Dimensões formativas de disciplinas do ensino básico. Ciências da natureza. Lisboa: Instituto de Inovação Educacional.

Monteiro, A. (1977). Educação. Acto político. Lisboa: Livros Horizonte.

Ozdem-Yilmaz, Y e Cavas, B. (2016). Pedagogically desirable science education: Views on inquiry-based Science Education in Turkey. Journal of Baltic Science Education, 15(4), 506- 
doi: http://dx.doi.org/10.15359/ree.21-1.16

URL: http://www.una.ac.cr/educare

CORREO: educare@una.cr

522. Recuperado de http://www.scientiasocialis.lt/jbse/files/pdf/vol15/506-522.OzdemYilmaz JBSE Vol.15 No.4.pdf

Pereira, M. P. (Coord.). (1992). Didáctica das ciências da natureza. Lisboa: Universidade Aberta.

Piel, E. J. (1980). VII. Interaction of science, technology, and society in secondary schools. In N. C. Harms e R. E. Yager (Eds.), What research says to the science teacher (Vol. 3, pp. 94-112. Washington: National Science Teachers Association-NSTA.

Porlán, R. e Martín, R. (2004). The conceptions of in-service and prospective primary school teachers about the teaching and learning of science. Journal of Science Teacher Education, 15(1), 39-62. doi: https://doi.org/10.1023/B:JSTE.0000031462.40615.56

Porlán, R., Rivero, A. e Martin, R. (1998). Conocimiento profisional y epistemología de los profesores, II: Estudios empíricos y conclusiones. Enseñanza de las Ciencias, 16(2), 271-288. Recuperado de https://ddd.uab.cat/pub/edlc/02124521v16n2/02124521v16n2p271.pdf

Reis, P. (2013). Da discussão à ação sociopolítica sobre controvérsias sócio-científicas: Uma questão de cidadania. Ensino de Ciências e Tecnologia em Revista, 3(1), 1-10. Recuperado de $\quad$ http://repositorio.ul.pt/bitstream/10451/9577/3/DA\%20DISCUSS\%C3\%830\%20 \%C3\%80\%20A\%C3\%87\%C3\%830.pdf

Roso, C. C. e Auler, D. (2016) A participação na construção do currículo: Práticas educativas vinculadas ao movimento CTS. Ciência \& Educação (Bauru), 22(2), 371-389. Recuperado de http://www.scielo.br/pdf/ciedu/v22n2/1516-7313-ciedu-22-02-0371.pdf

Rubba, P. A., Jr. (1982). Scientific literacy: The decision is ours. In J. Staver (Ed.), An analysis of the secondary school science curriculum and directions for action in the 1980's (pp. 45-62). Ohio: AETS.

Sá, J. e Varela, P. (2007). Das ciências experimentais à literacia. Porto: Porto Editora.

Sá, J., Varela, P., Carvalho, G. S. e Guimarães, F. (1999). Manual do professor para o ensino experimental no $1^{\circ}$ ciclo. Um projecto de investigação-acção centrado na escola. In R.V. Castro, A. Rodrigues, J. L. Silva e M. L. D. Sousa (Eds.), Manuais escolares. Estatuto, funções, história: Actas do I encontro internacional sobre manuais escolares (pp. 441-458). Braga: Instituto de Educação e Psicologia, Universidade do Minho.

Santos, M. E. (1998). Mudança conceptual na sala de aula. Um desafio pedagógico epistemologicamente fundamentado ( $2^{\mathrm{a}}$ ed.). Lisboa: Livros Horizonte.

Santos, W. L. P. (2007) Educação científica na perspectiva de letramento como prática social: Funções, princípios e desafios. Revista Brasileira de Educação, 12(36), 474-492. Recuperado de http://www.scielo.br/pdf/rbedu/v12n36/a07v1236.pdf 
doi: http://dx.doi.org/10.15359/ree.21-1.16

URL: http://www.una.ac.cr/educare

CORREO: educare@una.cr

Schwab, J. J. e Klinckman, E. (1970). Manual do professor de biologia (BSCS). Lisboa: Gulbenkian.

Science/technology/society:Aneweffortforprovidingappropriatescienceforall [Editorial].(1990). Bulletin of Science, Technology \& Society, 20, 249-250. doi: 10.1177/0270467690010005-601

Solís, E., Porlán, R. e Rivero, A. (2012). ¿Cómo representar el conocimiento curricular de los profesores de ciencias y su evolución? Enseñanza de las Ciencias. Revista de Investigación y Experiencias Didácticas, 30(3), 9-30. Recuperado de http://www.raco.cat/index.php/ Ensenanza/article/viewFile/285681/373653.

Tamir, P. (1989). Science education: Curriculum reform. In T. Husén e T. N. Postlethwaite (Eds.), The international encyclopedia of education (Vol. suplementary I, pp. 664-8). Oxford: Pergamon Press. doi: https://doi.org/10.1002/sce.3730730106

Tuay, R. N. \& Porras, Y. A. (2015). Representaciones de la naturaleza de la ciencia y la tecnología desde la perspectiva CTSA de profesores en escuelas normales superiores. Revista Científica, 3(23), 30-42. Recuperado de http://revistas.udistrital.edu.co/ojs/index.php/revcie/article/ view/9048/11027

Valente, M. O., Gaspar, A., Lobo, A., Salema, M.H., Morais, M.M. e Cruz, M.N. (1989). Aprender a pensar. Lisboa: Departamento de Educação da FCUL, Projecto Dianoia.

Valente, M. O., Gaspar, A., Rainho, M.A.., Salema, M.H., Santos, M.E., Morais, M.M. e Cruz, M.N. (1991). Programas para Aprender a Pensar. Lisboa: Departamento de Educação da FCUL, Projecto Dianoia.

Welch, W. W. (1980). V. Inquiry in school science. Em N. C. Harms e R. E. Yager (Eds.), What research says to the science teacher (Vol. 3, pp. 53-72). Washington: National Science Teachers Association. doi: https://doi.org/10.1111/j.1949-8594.1980.tb09554.x 